\title{
BMJ Open Cross-sectional study of the financial cost of training to the surgical trainee in the UK and Ireland
}

\author{
John O'Callaghan, Helen M Mohan, Anna Sharrock, Vimal Gokani, \\ J Edward Fitzgerald, Adam P Williams, Rhiannon L Harries, on behalf of the \\ Council of the Association of Surgeons in Training
}

\begin{abstract}
To cite: 0'Callaghan J, Mohan HM, Sharrock A, et al. Cross-sectional study of the financial cost of training to the surgical trainee in the UK and Ireland. BMJ Open 2017;7:e018086. doi:10.1136/ bmjopen-2017-018086

- Prepublication history and additional material for this paper are available online. To view these files, please visit the journal online (http://dx.doi. org/10.1136/bmjopen-2017018086).
\end{abstract}

Received 6 June 2017

Revised 23 September 2017

Accepted 26 September 2017

CrossMark

Association of Surgeons in Training, London, UK

Correspondence to Rhiannon L Harries; rhiannon.harries@doctors. org.uk

\section{ABSTRACT}

Objectives Applications for surgical training have declined over the last decade, and anecdotally the costs of training at the expense of the surgical trainee are rising. We aimed to quantify the costs surgical trainees are expected to cover for postgraduate training.

Design Prospective, cross-sectional, questionnaire-based study.

Setting/Participants A non-mandatory online questionnaire for UK-based trainees was distributed nationally. A similar national questionnaire was distributed for Ireland, taking into account differences between the healthcare systems. Only fully completed responses were included.

Results There were 848 and 58 fully completed responses from doctors based in the UK and Ireland, respectively. Medical students in the UK reported a significant increase in debt on graduation by $55 \%$ from $£ 17892$ (2000-2004) to $£ 27655(2010-2014)(p<0.01) .41 \%$ of specialty trainees in the UK indicated that some or all of their study budget was used to fund mandatory regional teaching. By the end of training, a surgical trainee in the UK spends on average $£ 9105$ on courses, £5411 on conferences and $£ 4185$ on exams, not covered by training budget. Irish trainees report similarly high costs. Most trainees undertake a higher degree during their postgraduate training. The cost of achieving the mandatory requirements for completion of training ranges between $£ 20000$ and $£ 26000$ (dependent on specialty), except oral and maxillofacial surgery, which is considerably higher (£71 431).

Conclusions Medical students are graduating with significantly larger debt than before. Surgical trainees achieve their educational requirements at substantial personal expenditure. To encourage graduates to pursue and remain in surgical training, urgent action is required to fund the mandatory requirements and annual training costs for completion of training and provide greater transparency to inform doctors of what their postgraduate training costs will be. This is necessary to increase diversity in surgery, reduce debt load and ensure surgery remains a popular career choice.

\section{INTRODUCTION}

The number of trainees applying for surgical training has declined over the last decade. ${ }^{1}$ Many factors including low workforce morale,

\section{Strengths and limitations of this study}

- This national study provides a large cross-sectional data set on the experience of the costs of surgical training by surgical trainees across all 10 surgical specialties in the UK and Ireland.

- The costs analysed provided a comprehensive overview of the breadth and depth of financial costs incurred by trainees.

- The wide distribution of the survey and breadth of responses increased the likelihood that it is representative of trainee experience.

- We recognise that there is a significant number of surveys excluded due to incompletion, which we believe to be related to the need for accurate costings to compete the survey. However, the overall number of completed responses was higher than required to power the study.

- It is recognised that some costs could be subject to recall bias or an element of selection bias, in that those with significantly more debt may be more likely to respond; however, the figures reported are largely consistent with the calculations we have made using the current prices of exams, courses and society memberships to verify the results.

poor work-life balance and recent contractual issues may act as a deterrent to medical students considering a career in surgery. ${ }^{2}$ The cost of completing the mandatory postgraduate requirements to secure a higher surgical training programme post has been estimated to be between $£ 2735$ and $£ 20780$, dependent on surgical specialty (average £3360), compared with medicine (£2815) and anaesthetics (£2215). ${ }^{3}$ Following entry to higher surgical training, there are considerable ongoing costs incurred by trainees in order to meet the requirements for completion of training as mandated by the Joint Committee on Surgical Training (JCST). These include educational courses, conference attendance, Royal College membership and fellowship examinations and annual subscriptions, and specialty society 
membership subscriptions. In addition, trainees pay annual expenses such as registration with the respective regulatory bodies, the UK General Medical Council or the Irish Medical Council (IMC), medical indemnity insurance costs, and the JCST fee (paid by trainees in the UK).

In 2007, the Association of Surgeons in Training (ASiT) conducted a survey of UK surgical trainees to assess the financial costs to trainees in surgical training. ${ }^{4}$ The results demonstrated that the mean debt on qualification from medical school was over $£ 20000$. However, in recent years there have been many new challenges facing the current generation of surgical trainees, including increased student debt, secondary to a rise in annual university tuition fees of up to $£ 9000$ per annum. ${ }^{5}$ It has previously been calculated that medical students graduating currently are unlikely to repay their student loan debt before reaching the 30 -year point at which it is written off. ${ }^{6}$ The salaries of male and female medical graduates diverge such that by the age of 55 , the average male medical school graduate earns $35 \%$ more. $^{6}$ This means that the average female graduate repays more when debt is low, but a lower amount when debt is high, compared with male graduates. ${ }^{6}$ The cost of living has also increased; in the 10 years preceding November 2016 , the UK consumer price index rose to a total of $23.8 \%{ }^{7}$

To assess the current situation, we repeated a refined study, with a broader remit and more in-depth assessment of cost pressures on trainee surgeons in both the UK and Ireland. The main aim was to assess the true financial cost of training to the surgical trainee in each of the 10 surgical specialties.

\section{METHODS}

\section{Participants and setting}

Postgraduate surgical training in the UK and Ireland consists of a minimum of 8 years of training (except for oral and maxillofacial surgery (OMFS) and urology, which is a minimum of 7 years) following completion of the initial postqualification 2-year Foundation Programme (or intern year in Ireland) (figure 1). Competitive entry occurs prior to both core and higher specialist training levels, except for neurosurgery, cardiothoracic surgery and OMFS in the UK (and trauma and orthopaedics in Scotland), where 'run-through' training (no separate selection process between core and higher specialist training) from core level exists. Core surgical knowledge is assessed by the Intercollegiate Membership of the Royal College of Surgeons examination, and specialty-specific knowledge during the later phase of higher surgical training is assessed by the Intercollegiate Fellowship of the Royal College of Surgeons examination.

In the UK and Ireland, the JCST is responsible for curriculum development and quality assurance of all the surgical training programmes in the 10 defined surgical specialties (cardiothoracic surgery, general surgery, neurosurgery, OMFS, otolaryngology, paediatric surgery, plastic surgery, trauma and orthopaedics, urology, and

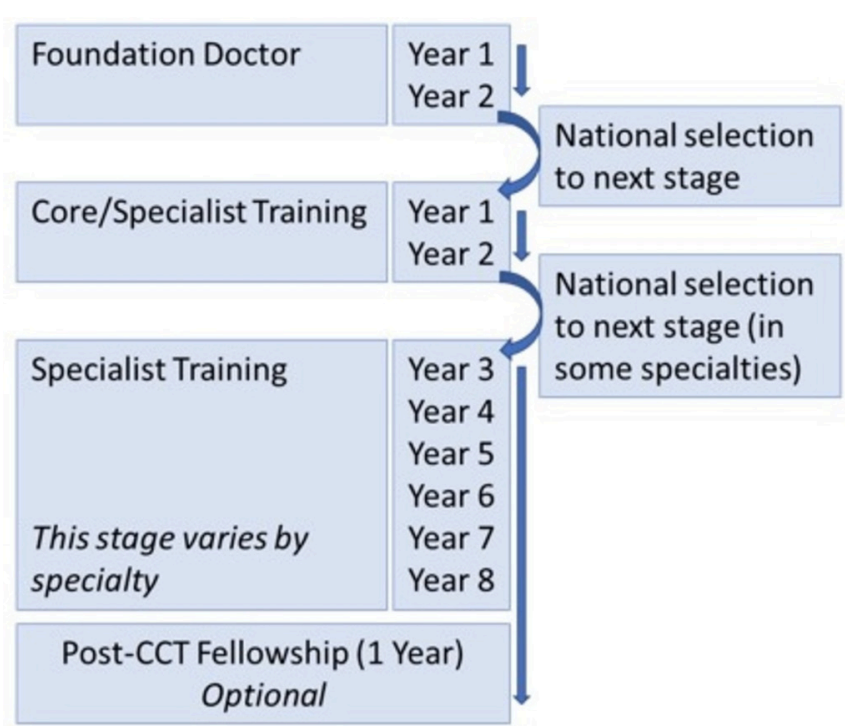

Figure 1 Stages and years of training for UK doctors training to be consultant surgeons. Foundation doctor year 1 is the first stage following graduation from university/ medical school. In Ireland, the intern year is the equivalent of the foundation doctor stage in the UK. CCT, Certificate of Completion of Training.

vascular surgery). All surgical trainees are required to register with the JCST and to pay an annual fee ( $£ 255$ at time of submission) that has more than doubled between 2010 and 2016. This fee supports the running costs of the JCST to manage trainee enrolment and recommendation for certification; the work of each of the 10 surgical specialties' 'Specialty Advisory Committee' (SACs); curriculum review and development; and website support. The JCST training fee is covered for trainees in Ireland directly by funding received by the Royal College of Surgeons of Ireland (RCSI) from the Health Service Executive (HSE).

In the UK, Local Education Training Boards (LETBs) provide funding to local education providers (essentially the hospital where a trainee is employed) to cover the direct costs of delivering education and training. This sum includes two components: first, salary support of $50 \%$ of each doctor's basic salary; and the second component is a placement fee of $£ 12400$ per year, per trainee, to fund all costs involved in delivering education and training needs. It is from this placement fee that trainees apply for study funding support towards courses and conferences essential to their training, often referred to as 'study leave budget', with a restricted amount available dependent on the LETB. Funding for military trainees in the UK regular Defence Medical Services is overseen by External Education and Training Support within the Defence Deanery. Funding for training courses for military trainees is therefore at the discretion of the Defence Consultant Advisor and Defence Deanery. ${ }^{8}$ In Ireland, the RCSI receives funding from HSE to provide surgical training, which covers the cost of the JCST fee, delivering the curriculum, human factors and operative skills training days. However, other elements essential for Certificate of Completion of Training (CCT) are not directly provided. More details of 
funding for Irish trainees are given in online supplementary appendix 1 .

At the time of survey distribution, there were 5323 surgical trainees in the UK and 438 surgical trainees in Ireland. ${ }^{9}$

\section{Questionnaire design and distribution}

A novel 54-item survey tool was developed, consisting of free-text, binomial and variable scale responses. The questionnaire was designed with reference to previously published guidelines on conducting questionnaire research. ${ }^{10-12}$ The online platform SurveyMonkey (Palo Alto, California, USA; www.surveymonkey.com) was used to build the survey. All individual question items were compulsory. No individually identifiable information was collected; therefore, non-responders could not be identified for follow-up. No incentives were offered for participation. A link to the online survey was distributed to the members of ASiT, surgical specialty associations, and local and national mailing lists of surgical trainees. All surgical trainees in the UK including foundation doctors were included, as appropriate to the level of analysis. A modified version of the survey was circulated to ASiT members and surgical trainees in Ireland, which reflected relevant differences in health systems and training. Interns were excluded from distribution of the survey in Ireland as contact details were only available for those registered as surgical trainees with RCSI. Data collection took place from 2 December 2015 to 26 April 2016. Participants consented to the use of the analysis, distribution and publication of anonymised grouped results. A copy of the survey can be found in online supplementary appendix 2 .

This study was undertaken by ASiT (http://www.asit. org), a pan-surgical specialty professional body and registered charity in the UK (no: 274841) working to promote excellence in surgical training for the benefit of junior doctors and patients alike. ASiT is independent of the National Health Service, Surgical Royal Colleges and specialty associations.

\section{Data analysis}

Only fully completed questionnaires were included in the analysis. Due to the differing healthcare structures and funding systems of postgraduate education and training in UK and Ireland, a modified version of the survey was used for Ireland and the results are presented separately. Military trainees were excluded due to low numbers and a separate training funding structure. Data were graphed and analysed in Excel (Microsoft, Redmond, Washington, USA). Significance testing for continuous variables was conducted using Mann-Whitney U test in Stata 14; statistical significance was accepted at $\mathrm{p}<0.05$. Survey sample size calculations were based on standard published formulae, and assuming a population of 6000 individuals, with alpha $=0.01$, 209 responses would be sufficient for a margin of error of $0.03 .{ }^{13}$ For readability, all values are presented to the nearest pound $(£)$ or euro $(€)$. We have used the exchange rate as accessed on 13 January 2017 of $£ 0.87=€ 1.00$ to provide comparisons between the two currencies. ${ }^{14}$ The study results are reported in concordance with the STROBE (Strengthening the Reporting of Observational Studies in Epidemiology) guidance on observational studies. ${ }^{15}$ Results regarding costs are presented displaying trainees' year of graduation in blocks of 5 years to show trends over time.

\section{Costs of CCT to the trainee in each surgical specialty}

Using guidance available from the JCST, the total cost of achieving the mandatory and desirable requirements for CCT in each of the surgical specialties was also calculated. Where conference attendance was mandated, but no exact minimum number described, the cost of at least one attendance during the training period was calculated. For courses that required revalidation at the end of training, the reduced course cost of revalidation rather than a full attendance was used. Course costs from recognised bodies, such as the British Medical Association (BMA) and Surgical Royal Colleges, were used in all calculations, where applicable. Conference costs were calculated using the reduced rates available to society members or early registrations where possible.

\section{RESULTS}

Of 1603 surveys submitted, a total of 868 fully completed responses were included in the analysis from doctors based in the UK and 58 fully completed responses from doctors based in Ireland. Respondent demographics by country of work are detailed in table 1 .

\section{UK-specific responses}

For the purposes of monetary analysis, UK military doctors $(n=20)$ were excluded from the main analysis; however, a summary of military doctors' survey findings can be found in online supplementary appendix 3 . This resulted in a total of 848 respondents for analysis. Of 848 respondents, 751 (88\%) graduated from medical school in the UK. Eighty-nine per cent (672) of these UK medical school graduates graduated with debt, with a mean of $£ 25404$. The average debt by year of graduation has increased by $55 \%$ from $£ 17892$ to $£ 27655$, comparing graduates in the most recent generation (2010-2014)

\begin{tabular}{|c|c|c|}
\hline Demographics & UK & Ireland \\
\hline$n$ & 848 & 58 \\
\hline Male:female (\%) & $\begin{array}{l}\text { 518:327 (61.3:38.7, } \\
3 \mathrm{NR})\end{array}$ & $35: 23(60: 40)$ \\
\hline Mean age (years) & 31.6 (range 23-55) & 31.3 (range 25-41) \\
\hline $\begin{array}{l}\text { LTFT trainees } \\
(\%)\end{array}$ & $36(4.3)$ & 0 \\
\hline $\begin{array}{l}\text { Academic } \\
\text { trainees (\%) }\end{array}$ & $69(8.1)$ & N/A \\
\hline
\end{tabular}

Respondents divided by country of work.

LTFT, less than full-time training; N/A, not applicable; NR, not reported. 


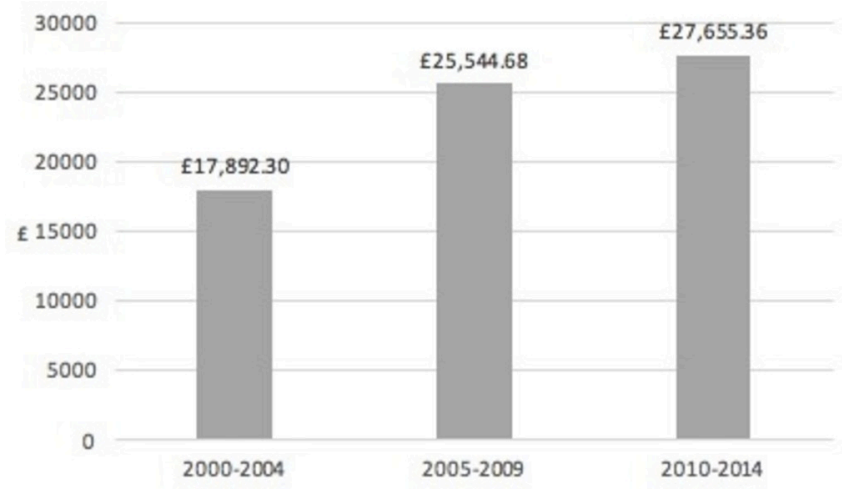

Figure 2 Mean debt on graduation from medical school, UK medical schools only. Debt has increased significantly comparing the most recent generation (graduation between 2010 and 2014) with the older generation (graduation between 2000 and 2004) $(p<0.01)$.

with those graduating between 2000 and $2004(\mathrm{p}<0.01)$ (figure 2).

There were 659 specialty trainee respondents from the UK (grades core training (CT)/specialist training (ST) ST1 to ST8) (table 2). Of these, 93\% (618) responded that they were currently entitled to a study leave budget. The median value was $£ 600$ per annum (range $£ 500$ $£ 835)$. Three LETBs reported no defined budget limit (Yorkshire and Humber, South West, and Thames Valley). Of all respondents in specialty training, $41 \%$ indicated that some (31\% of respondents) or all (10\% of respondents) of their study budget was used to fund mandatory regional teaching.

By the end of training, a surgical trainee in the UK can expect to have spent on average $£ 9105$ on courses, $£ 5411$ on conferences and $£ 4185$ on exams ( $£ 18701$ ) that they have not been reimbursed through any source. Expense per year on conferences has marginally increased from

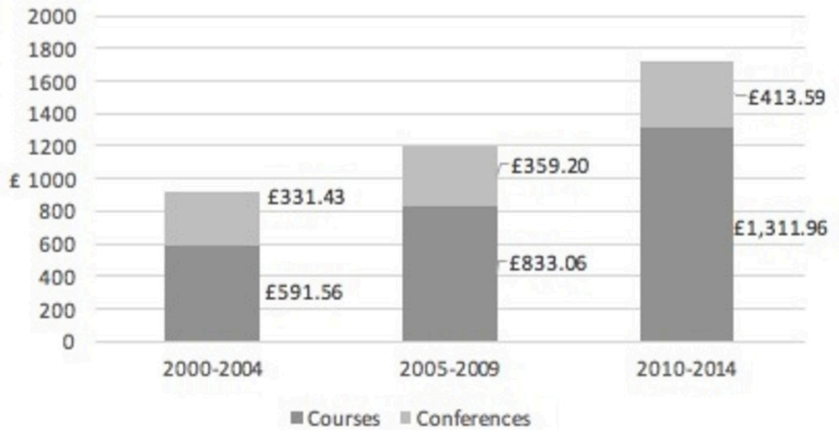

Figure 3 Mean expense per year on courses and conferences that trainees have not been reimbursed. Trainees grouped into 5-year generations by year of graduation. Expense on courses has increased significantly comparing the most recent generation (graduation between 2010 and 2014) with the older generation (graduation between 2000 and 2004) $(p<0.01)$. Expense on conferences has not significantly increased $(p=0.28)$. UK medical school graduates only.

$£ 331$ to $£ 414$, comparing older graduates with the more recent generation (2000-2004 vs 2010-2014, $\mathrm{p}=0.28$ ). However, course expenses per year have increased significantly; the most recent graduates from medical school, graduating in the years 2010-2014, have spent on average $£ 1311$ per year. This is an increase of $121 \%$ on the annual amount spent by medical school graduates graduating between 2000 and $2004(\mathrm{p}<0.01)$ (figure 3).

Four hundred respondents $(47 \%)$ from the UK have undertaken a postgraduate degree since graduating from medical school, with this proportion rising by the later stages of training (ST7-8 and post-CCT fellow) to $68 \%$ $(96 / 141)$. The average cost of the degree, including university fees and loss of earnings, was estimated by respondents at $£ 18009$, with an $\mathrm{MD} / \mathrm{PhD}$ being the most

Table 2 Specialty, stage of training and LETB for respondents from UK

\section{Which specialty do you intend to} pursue?

Cardiothoracic surgery: $32(3.8 \%)$
General surgery: $296(34.9 \%)$
Neurosurgery: 28 (3.3\%)
Oral and maxillofacial: $19(2.2 \%)$
Otolaryngology: $75(8.8 \%)$
Paediatric surgery: $29(3.4 \%)$
Plastic surgery: 66 (7.8\%)
Trauma and orthopaedics: 172 (20.3\%)
Vascular surgery: 59 (5.4\%)
Urology: 59 (7.0\%)
Other/Unsure: $26(3.1 \%)$

Other/Unsure: 26 (3.1\%)

What is your stage of training?

Foundation year 1: $12(1.4 \%)$
Foundation year 2: $63(7.4 \%)$
ST1/CT1/SHO1: $148(17.5 \%)$
ST2/CT2/SHO2: $96(11.3 \%)$
CT3/SHO3: $10(1.2 \%)$
ST3/SPR1: $78(9.2 \%)$
ST4/SPR2: $59(7.0 \%)$
ST5/SPR3: $77(9.1 \%)$
ST6/SPR4: $59(7.0 \%)$
ST7/SPR5: $60(7.1 \%)$
ST8/SPR6: $67(7.9 \%)$
Post-CCT: $17(2.0 \%)$
Clinical fellow: $35(4.1 \%)$
Research post: $53(6.3 \%)$
Other: $14(1.7 \%)$

Foundation year 1: $12(1.4 \%)$

ST1/CT1/SHO1: 148 (17.5\%)

ST2/CT2/SHO2: 96 (11.3\%)

(1.2\%)

ST6/SPR4: $59(7.0 \%)$

ST7/SPR5: $60(7.1 \%)$

ST8/SPR6: 67 (7.9\%)

Post-CCT: 17 (2.0\%)

Research post: 53 (6.3\%)

Other: 14 (1.7\%)
In which LETB/deanery do you work?

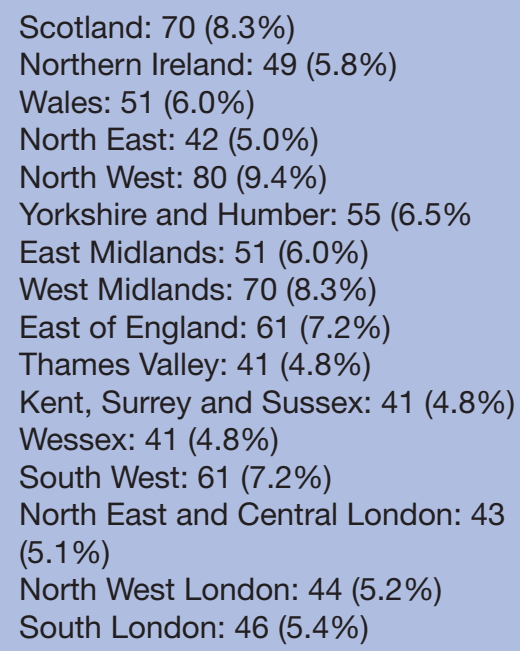

CCT, Certificate of Completion of Training; CT, coretraining; LETB, Local Education Training Board; SHO, senior house officer; SPR, specialist registrar; ST, specialist training. 
Table 3 Specialty and stage of training for respondents from Ireland

\begin{tabular}{ll}
\hline $\begin{array}{l}\text { Which specialty do you intend } \\
\text { to pursue? }\end{array}$ & $\begin{array}{l}\text { What is your stage of } \\
\text { training? }\end{array}$ \\
\hline Cardiothoracic surgery: $2(3 \%)$ & ST1/CT1/SHO1: $13(22 \%)$ \\
General surgery: $22(38 \%)$ & ST2/CT2/SHO2: $10(17 \%)$ \\
Neurosurgery: $1(2 \%)$ & ST3/SPR1: $12(21 \%)$ \\
Oral and maxillofacial: 0 & ST4/SPR2: $5(9 \%)$ \\
Otolaryngology: 2 (3\%) & ST5/SPR3: $4(7 \%)$ \\
Paediatric surgery: 0 & ST6/SPR4: $2(3 \%)$ \\
Plastic surgery: 3 (5\%) & ST7/SPR5: $1(2 \%)$ \\
Trauma and orthopaedics: 20 & ST8/SPR6: $3(5 \%)$ \\
(34\%) & Clinical fellow: $1(2 \%)$ \\
Vascular surgery: $2(3 \%)$ & Research post: $1(2 \%)$ \\
Urology: $6(10 \%)$ & \\
\hline
\end{tabular}

$\mathrm{CT}$, core training; SHO, senior house officer; SPR, specialist registrar; ST, specialist training.

popular higher degree completed (24.8\%, mean cost £27 882), followed by MSc (21.3\%, mean cost £11 090).

Seven hundred and thirty-two respondents from the UK $(86 \%)$ and 340 of 349 trainees level ST3-ST8 $(97 \%)$ pay an annual subscription to one of the four Surgical Royal Colleges (mean $£ 305$ for all trainees, mean $£ 386$ for ST3-ST8). Seven hundred respondents (82\%) pay annually to their SAC-defined specialty society (mean £343) and $672(79 \%)$ are members of the BMA. Over the last year, the mean amount spent on journals was $£ 72$ and on textbooks was $£ 212$.

\section{Ireland-specific responses}

Of the 58 respondents, 57 were currently working in Ireland and one was on fellowship in the USA (tables 1 and 3). Twenty-five $(43 \%)$ reported that they were currently entitled to a training fund (see online supplementary appendix 1). In the past year, trainees spent on average $£ 1278$ (€1469) on mandatory courses, including travel expenses to courses, many of which are outside of Ireland, of which a mean of $£ 784$ (€902) was not reimbursed. Trainees spent a mean of $£ 1977$ ( $€ 2321$ ) on non-mandatory courses, of which a mean of $£ 1850$ (€2164) was not reimbursed. In the past year, respondents had spent a mean of $£ 1153$ (€1353) on attending conferences, of which a mean of $£ 1005$ (€1183) was not reimbursed. Since graduation, across all grades, trainees had spent a mean of $£ 4829$ (€5669) on examinations, of which a mean of £3402 (€4004) was not reimbursed. For senior trainees (ST8), an average of $£ 9796$ (€11 500 ) had been spent on exams, of which $£ 5396$ (€6351) was not reimbursed.

Forty-seven respondents $(\mathrm{n}=81 \%)$ from Ireland had undertaken a postgraduate degree since graduating from medical school. MCh was the most popular postgraduate degree $(n=15,26 \%)$, followed by MSc $(n=13,22 \%)$ and MD ( $\mathrm{n}=11,19 \%)$. The average estimated total monetary cost of undertaking a postgraduate degree to the trainee, including course fees and loss of income, was £22 093 (€25 936).
Estimated costs of training (UK and Ireland) using CCT essential and desirable criteria

The costs range between $£ 20000$ (€23 479) and £26000 (€30 523) depending on surgical specialty, except OMFS, which is considerably higher ( $£ 71431$ or $€ 83$ 858) due to the dual qualification in medicine and dentistry, as well as having significantly more mandatory training courses than other specialties (see online supplementary appendix 4).

Only the minority of the costs are tax-deductible, add to this the estimated cost of a postgraduate degree ( $£ 18009$ or $€ 21$ 142), which many surgical trainees will also undertake at their own expense, and the estimated costs to the trainee increase to approximately $£ 40000$ (€46 958, excluding OMFS).

\section{DISCUSSION}

This study has shown that individual doctors incur many thousands of pounds in personal expense after graduating from medical school to pursue a career as a surgeon and to meet the requirements to complete surgical training. These costs are incurred in addition to the significant debt built up by most medical school graduates, a debt burden likely to rise further as a greater proportion of students graduate under increased student tuition fees in the UK. Many of the costs paid by the trainee towards their training are not recognised as tax-deductible, yet are incurred to cover requirements that are essential to progress through training schemes and therefore to maintain one's livelihood. Consultant surgeons-to-be now spend considerably more per year on courses than in the past, and these now represent the single largest training cost, according to our results. Efforts to make surgery an attractive and inclusive career must include an equitable distribution of training costs to the trainee.

Individual trainees spend significant amounts on courses that are not actually mandatory as documented in CCT requirements. We speculate there are two reasons for this: first, surgical trainees will undertake courses above and beyond the minimum requirements to develop their skills. Gaps in knowledge and experience delivered in current training posts are likely to contribute to this, such that simulation courses are necessary to address training needs. As such, issues with training programmes failing to meet trainees' educational needs are instead transferred to trainees, who still obtain this necessary training at their own cost. Second, to be competitive for higher surgical training and for consultant posts, trainees may undertake additional courses and extracurricular activities.

We have identified a regional variation in what amount is available to trainees, despite the standardised placement fee from the LETB. Study budgets for specialty trainees were lower than the values released in response to the recent freedom of information (FOI) request by Varley $e t a l^{16}$ in 7 out of 10 LETBs (North Central, South and North West London, North West England, East of England, Kent, Surrey and Sussex, and North East 
England), and equal in three LETBs (East Midlands, Wales and West Midlands). It is desirable that study budgets are standardised across the UK, in both amounts, and that they should not be top-sliced to provide mandatory regional teaching, and in the longer term all items deemed essential for CCT (including the JCST fee) should be funded directly, without expense to the trainee. ASiT has previously highlighted this issue of uncontrolled geographical variation, calling for an equitable approach through national standardisation. ${ }^{17}$

Irish trainees bear similar high costs in surgical training to their UK counterparts, not surprisingly given that JCST requirements are the same. The higher cost of courses for Irish trainees may reflect increased travel and accommodation expenses, as many courses require travel outside of Ireland and the exclusion of Irish interns from the study, who are less likely to have undertaken expensive technical skills courses. The higher cost of exams may reflect in part a higher proportion of Irish trainees who undertake United States Medical Licensing Examination (USMLE) examinations to pursue a fellowship in the USA, as well as increased travel expenses to intercollegiate examinations often held in the UK. While funding is available to reimburse some of these expenses, it falls short of being sufficient to avoid trainees bearing the greatest burden of the cost. These costs are on top of annual mandatory costs such as membership or fellowship of RCSI. These are significant additional costs-for example, the 2016/2017 subscription rate is $£ 315$ (€370) for fellows and £226 (€265) for members, and the annual IMC retention fee $(£ 477(€ 560)$ for those registered for less than 3 years and $£ 515$ (€605) for those registered for more than 3 years). Of note, the payment for the IMC is an annual payment and cannot be split across the year, which places a significant financial burden on trainees at the time of the year when they move jobs and incur considerable additional expenses.

Sixty-eight per cent of later stage higher surgical trainees in the UK and $81 \%$ of Irish trainees report obtaining a higher degree. This was associated with an average cost estimated by respondents of over $£ 18000$ and $£ 22000$ in the UK and Ireland, respectively. While it is not deemed mandatory by the JCST to undertake a higher degree within surgical training, there are a number of reasons why surgical trainees choose to undertake one. First, it is required in order to practise as an academic consultant surgeon, and second a significant proportion of trainees will undertake one in order to make themselves competitive for consultant appointment.

Doctors need to be aware in advance of what their chosen pathway is likely to cost them, alongside the starting salary for consultant posts when they complete their training (ranging from $£ 76761$ in the UK and $£ 95775$ (€105 000) in Ireland ${ }^{18}{ }^{19}$ ). This study has provided the most detailed assessment yet for both UK and Irish surgical trainees. It is difficult to compare the costs with other medical specialties as few similar studies have been undertaken in other disciplines. One calculation for the training costs towards the completion of CCT in obstetrics and gynaecology estimated slightly less than for surgical trainees, at $£ 14224 .^{20}$ Another calculation for only the early stages of training in other specialties was also slightly less for medicine and anaesthetics than surgical specialties. ${ }^{3}$ Comparisons with other professional careers, such as solicitors, are also difficult, but working in the private sector has additional benefits. After qualifying with a law degree, solicitors must complete a legal practice course, which costs $£ 8500-£ 15000$ dependent on the type of course and location. ${ }^{21}$ It is however possible to have this cost covered by a law firm if obtaining a training contract in advance, and many law firms will also provide a living expense grant of several thousand pounds per year. ${ }^{22}$

Research by the University of Kent for the Department of Health has provided cost estimates for the training of various doctor grades from the start of medical school onwards. ${ }^{23}$ This work found that the total cost of training a consultant was $£ 564112$, with some contributions that came largely from the individual (such as undergraduate university fees, lost earnings and postgraduate training fees) and others that came predominantly from the state (clinical placement, tuition and replacement) ${ }^{23}$ It is not possible from the document to disentangle the values independently contributed by each party.

An important consideration frequently overlooked in these analyses relates to the hospital activity performed by trainees generating hospital income. Doctors in training have a value as well as a cost, which should be taken into account to offset such cost estimates. Two UK-based studies have sought to quantify this within surgical training. ${ }^{24}{ }^{25} \mathrm{In}$ general surgery, an analysis of 1184 outpatient clinic consultations demonstrated that trainees delivered a quarter of all outpatient-related income, averaging $£ 36452$ per trainee. ${ }^{24}$ This was sufficient to offset $95 \%$ of the trainees' average basic salaries. Within otolaryngology surgery, clinical activity undertaken by senior house officer (SHO) or core surgical trainee level grade doctors was calculated to generate an annual net income of $£ 73048$ (4.3 times higher than their employment costs).$^{25}$ Registrars generated an annual net income of $£ 121587$ (5.4 times their employment cost). In total, $94 \%$ of trainees included in this analysis generated more hospital income than their employment costs. Given the benefit derived from hospitals from trainee-related clinical activity, it is reasonable that a proportionate amount of the associated costs of training should be borne by the employing hospitals.

The costs analysed in this study present a comprehensive overview of the breadth and depth of costs incurred by trainees. The survey was widely distributed across regions, specialties and grades, increasing the likelihood that it is representative of trainee experience. However, these results are specific to the UK and Ireland, and caution should be taken when comparing with other national surgical training systems due to international variability of the requirements for completion of training, length of training programme, differing training costs and salaries. A significant number of surveys were excluded due to incompletion, which we believe to be related to the need for accurate costings to compete the survey. However, the overall number of 
completed responses was higher than required to power the study. It is also recognised that some costs could be subject to recall bias or an element of selection bias, in that those with significantly more debt may be more likely to respond; however, the figures reported are largely consistent with the calculations made using the current prices of exams, courses and society memberships (see online supplementary appendix 4). Future studies should seek to understand the balance of costs incurred by the health system in supporting training, which are poorly understood, the influence of training cost on career choice, and wider international comparisons on the costs of training in different health systems.

\section{CONCLUSIONS}

Medical students are graduating with increasing debt. Surgical trainees achieve their educational requirements through considerable personal expenditure, with a total estimated monetary cost to the trainee in the region of $£ 40000$ $(€ 47$ 000). The CCT in surgical specialties comes with significant costs, which until now have not been accurately estimated. The cost goes far beyond the national training fee paid to the JCST annually in the UK, and greater transparency is immediately necessary to inform doctors of what their postgraduate training costs will be across all specialties. We strongly believe that the costs of mandatory surgical training should be covered by the LETBs, including the JCST fee and the costs of achieving CCT mandatory requirements. Furthermore, funding should be made available for non-mandatory surgical educational activity deemed beneficial by the trainee's educational supervisor to ensure surgeons are trained to the highest level to provide excellent care. This is necessary to increase diversity in surgery, reduce debt load and make surgery a popular career choice again.

Acknowledgements We thank all those trainees who took the time to complete the survey. We acknowledge the work done by JEFHe and Charles Giddings on the previous 2007 costs of surgical training survey.

Contributors RLH and JEF conceived the study. All authors designed the questionnaire. JOC collected the data. JOC, HMM and RLH analysed the data. All authors were responsible for compiling and editing the manuscript, and approving the final article.

Funding This research received no specific grant from any funding agency in the public, commercial or not-for-profit sectors.

Competing interests The authors are either current or previous surgical trainees, and current or past elected members of the Council of the Association of Surgeons in Training (registered charity no 274841). JEF is an employee of KPMG Global Health Practice, honorary clinical advisor to the Lifebox Foundation Charity and a trustee of the SURG Foundation Research Charity. The authors have no other relevant financial or personal conflicts of interest to declare in relation to this paper.

Ethics approval The ethical dimensions of this non-mandatory, anonymous evaluation survey were considered and no concerns were identified.

Provenance and peer review Not commissioned; externally peer reviewed.

Data sharing statement Summary data are available from the corresponding author at president@asit.org. Consent to data sharing was sought prior to survey completion, and the presented data are anonymised grouped, hence risk of individual identification is low.
Open Access This is an Open Access article distributed in accordance with the Creative Commons Attribution Non Commercial (CC BY-NC 4.0) license, which permits others to distribute, remix, adapt, build upon this work non-commercially, and license their derivative works on different terms, provided the original work is properly cited and the use is non-commercial. See: http://creativecommons.org/ licenses/by-nc/4.0/

(c) Article author(s) (or their employer(s) unless otherwise stated in the text of the article) 2017. All rights reserved. No commercial use is permitted unless otherwise expressly granted.

\section{REFERENCES}

1. Joint Committee for Surgical Training, National Selection Leads Group. Verbal communication. 2016.

2. Jaunoo SS, King TR, Baker RF, et al. A national survey of reasons why students and junior doctors choose not to pursue a career in surgery. The Bulletin of the Royal College of Surgeons of England 2014;96:192-4.

3. Stroman L, Weil S, Butler K, et al. The cost of a number: can you afford to become a surgeon? The Bull Royal Coll Surg Engl 2015;97:107-11.

4. Association of Surgeons in Training. The cost of surgical training, position statement. London, UK: Association of Surgeons in Training, 2007.

5. National Statistics. Student loans in England: 2015 to 2016. Glasgow, UK: Student Loans Company, 2016.

6. Ercolani MG, Vohra RS, Carmichael F, et al. The lifetime cost to english students of borrowing to invest in a medical degree: a gender comparison using data from the office for national statistics. BMJ Open 2015;5:e007335.

7. Statistical bulletin. UK consumer price inflation: Dec 2016. Office for National Statistics, 2016.

8. Defence healthcare education and training (DHET). Applications polic for defence medical services (DMS) external education and training, 4-6-3: Joint Services Publication, 2014.

9. Joint Committee on Surgical Training and Royal College of Surgeons in Ireland. Verbal communication. 2016.

10. Jones TL, Baxter MA, Khanduja V. A quick guide to survey research. Ann R Coll Surg Engl 2013;95:5-7.

11. Eysenbach $\mathrm{G}$. Improving the quality of Web surveys: the Checklist for Reporting Results of Internet E-Surveys (CHERRIES). J Med Internet Res 2004;6:e34.

12. Woodward CA. Questionnaire construction and question writing for research in medical education. Med Educ 1988;22:345-63.

13. Bartlett J, Kotrlik JW, Higgins C. Organizational research: determining appropriate sample size in survey research. Inf Tech Learn Perform J 2001;19:43-50.

14. ECB. Euro foreign exchange reference rates: european central bank. 2017.

15. von Elm E, Altman DG, Egger M, et al. The Strengthening the Reporting of Observational Studies in Epidemiology (STROBE) statement: guidelines for reporting observational studies. Lancet 2007;370:1453-7.

16. Varley I, Kumar A. Cost of training in oral and maxillofacial surgery: beyond the second degree. Br J Oral Maxillofac Surg 2016;54:956-8.

17. Fitzgerald JE, Giddings CE, Khera G, et al. Improving the future of surgical training and education: consensus recommendations from the Association of Surgeons in Training. Int J Surg 2012;10:389-92.

18. British Medical Association. Pay scales for consultants. 2017 https:// www.bma.org.uk/advice/employment/pay/consultants-pay-england.

19. Health Service Executive. Revised consolidated payscales. 2017 http://www.hse.ie/eng/staff/benefitsservices/pay/ConsolidatedPayscales-1st-April-2017.pdf.

20. Orr K, Smith M. The financial burden of specialty training. BMJ Careers 2016;353:542.

21. The Law Society. Costs of qualifying. 2017 http://www.lawsociety. org.uk/law-careers/becoming-a-solicitor/costs-of-qualifying/.

22. TargetJobs- Law. 2017.

23. Curtis L, Burns A. Unit costs of health and social care 2016: personal social services research unit. University of Kent, 2016.

24. Fitzgerald JE, Ravindra P, Lepore M, et al. Financial impact of surgical training on hospital economics: an income analysis of 1184 out-patient clinic consultations. Int J Surg 2013;11:378-82.

25. Clamp PJ, Malpas G, Mason KA, et al. Surgeons in training - a financial burden or benefit to NHS trusts? The Bull Royal Coll Surg Engl 2011;93:22-5. 